\title{
CHARACTERISTICS OF OIL-LUBRICATED PARTIALLY HERRINGBONE GROOVED JOURNAL BEARING
}

\author{
O.A.Abdelaal ${ }^{\star}$, A. A. Khalil ${ }^{\star \star}$ and A. M.Nasr ${ }^{\star *}$ \\ *Post graduate student,_osama_abdelaal@ymail.com \\ ** Professor, Mechanical Engineering Department, Faculty of Engineering, \\ Assiut University, 71516 Assiut
}

(Received May 20, 2009 Accepted June 18, 2009).

\begin{abstract}
An experimental investigation of the performance of oil-lubricated partially herringbone- grooved journal bearing (HGJBs) which have a beveled-step groove profile have been carried out. The bearing groove parameters (groove angle $\alpha$, groove width ratio $\beta$, groove depth ratio $\Gamma$ ) have been optimized for a wide range of bearing operating conditions in search of the best stability characteristics. Hydrodynamic lubrication unit with some accompanying apparatuses are used to measure the pressure distribution, attitude angle, Eccentricity, contact and friction torque. The optimized values are $\left(\alpha=26.78^{\circ}, \beta=0.55, \Gamma=2.2\right)$. The test results are compared to experimental results for the completely grooved bearing which have the same beveled-step groove profile [1] , and rectangular groove profile. In comparison of the previous work the introduced grooved configurations showed high radial stiffness and load capacity, low friction torque and better stability characteristics.
\end{abstract}

KEYWORDS: Hydrodynamic lubrication; herringbone grooved; partial grooving; load carrying capacity; pressure distribution; stiffness; groove profile.

\section{INTRODUCTION}

The journal bearings introduce viscous damping that aids in reducing the amplitude of vibrations in operating machinery. The dynamic and static characteristics of fluid-film bearings have a very significant effect on the overall dynamics of rotating machinery. These stability characteristics are greatly affected the plain journal bearing especially at concentric operation and the load capacity of the plain journal bearing approached an asymptotic value with increasing speed [2]. As well as the self-induced nonsynchronous vibration phenomenon (whirl), many bearing types have been developed to improve the stability. Herringbone grooved journal bearings (HGJBs) are the better alternatives. In $\left(\mathrm{HGJB}_{\mathrm{S}}\right)$ helical grooves can be machined on the surface of the shaft or bearing housing, also it can be machined on stationary or rotating member. The grooved surface can be completely or partially Herringbone grooved as shown in Figs. 1 and 2. The inward pumping action of these helical grooves in which the pressure distribution significantly changes within the bearing as shown in Fig. 3, generally improves load carrying capacity and stiffness.

Several theoretical techniques have been applied to analyze the performance of HGJBs. These techniques use two basic theoretical mathematical models: 
1- The narrow groove theory (NGT) which has been presented by Whipple (1958) and used by Hirs [3], Muijderman [4], Chow and Vohr [5], Hamrock and David [6], Bootsma [7], Kawabata et al. [8], and Yoshimoto et al. [9]. This theory presented an equation which is based on the limiting case of an idealized bearing for which the number of grooves approaches an infinite number and the flow is 2-d laminar flow. The result is a differential equation for the "overall" pressure distribution around HGJBs. The theory reduces the sawtooth circumferential pressure gradient into an averaged, overall pressure by assuming the fluctuations in pressure between the narrow grooves and ridges to be negligible. A numerical solution to the differential equation is obtained which is based on a perturbation in $\varepsilon$, and is valid for small eccentricities. This theory is known to give fairly accurate characteristics of gas lubricated HGJBs [10].

\section{NOMENCLATURE}

C Radial clearance at concentric position, $\mathrm{m}$

D Journal diameter, $m$

d Tool tip width, $\mathrm{m}$

e Journal eccentricity

$\overline{\mathrm{F}}_{\mathrm{R}} \quad$ Dimensionless radial stiffness

$\mathrm{Hg} \quad$ Groove depth, $\mathrm{m}$

$\mathrm{Hr} \quad$ Oil film thickness in ridge region, $\mathrm{m}$

$\mathrm{L} \quad$ Bearing length, $\mathrm{m}$

Lg Groove length in the circumferential direction, $\mathrm{m}$

$\mathrm{Lr} \quad$ Ridge length in the circumferential direction, $\mathrm{m}$

$\mathrm{Ng} \quad$ Number of grooves

$\mathrm{P} \quad$ Hydrodynamic oil film pressure, $\mathrm{N} / \mathrm{m}^{2}$

$\overline{\mathrm{P}} \quad$ Dimensionless pressure

$\mathrm{Pa}$ Ambient pressure, $\mathrm{Pa}=1.0$ bar

$\mathrm{R}$ Journal radius, $\mathrm{m}$

$\mathrm{T}_{\mathrm{r}} \quad$ Bearing friction torque, $\mathrm{N} \mathrm{m}$

$\overline{\mathrm{T}}_{\mathrm{r}} \quad$ Dimensionless friction torque

W Load carrying capacity, N

$\bar{W} \quad$ Dimensionless load carrying capacity
$\mathrm{X}, \mathrm{Y}, \mathrm{Z}$ Coordinate system fixed to the bearing

\section{Greek Symbols}

$\alpha \quad$ Groove angle, deg

$\beta \quad$ Groove width ratio

$\Gamma \quad$ Groove depth ratio

$\Lambda \quad$ Groove length ratio

$\varepsilon \quad$ Eccentricity ratio, $\varepsilon=\mathrm{e} / \mathrm{c}$

$\varphi \quad$ Bearing attitude angle, degrees

$\mu \quad$ Lubricant viscosity, N.s $/ \mathrm{m}^{2}$

$\theta \quad$ Angle measured from the location of the maximum oil film thickness in the direction of journal rotation, degrees

$\Theta \quad$ Bevel angle of the groove, degrees

$\omega \quad$ Journal rotational speed, rpm

$\Phi \quad$ Angle measured from the negative $\mathrm{Y}$ axis and in the direction of rotation $\Phi=\theta+\varphi$.

$\Lambda \quad$ Bearing number,

$$
\Lambda=\frac{6 \mu \omega}{P a}\left(\frac{R}{C}\right)^{2}
$$

2- The Reynolds equation in its various forms which includes the mathematical relationships between load, speed, clearance and the fluid properties of the lubricant. The equation has been solved by many mathematical techniques which are satisfying the appropriate boundary conditions. Finite element method (FEM) is 
used to solve the Reynolds equation to obtain pressure distribution, fluid film reaction forces, friction torque and dynamic coefficients. This method is used by Bonneau and Absi [11], Kinouchi et al. [12], Zirkelback and San Andres [13], Marco tulio c.faria [14], Jang and Yoon [15,16] and Jang et al. [17], also a finite difference (FDM) treatment of the Reynolds equation is used to investigates the performances characteristics of $\mathrm{HGJB}_{\mathrm{S}}$. FDM is used by Kang et al. [10], Kobayashi [18], Lee et al. [19], Hirayama et al. [20], and Cheng-Chi Wang [21]. A few results of the performance of $\mathrm{HGJB}_{\mathrm{S}}$ have been verified experimentally. Bootsma and Tielemans [22] had experimentally determined the operating conditions at which no leakage occurs for $\mathrm{HGJB}_{\mathrm{S}}$. Burton [23] carried out experiments on a spiral grooved bearing on a large scale turbulence apparatus. The test results show how the bearing load capacity varies with changes in the bearing clearance.

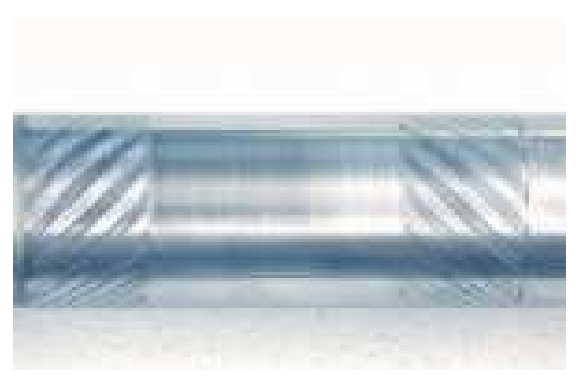

Fig. 1 Partially $\left(\mathrm{HGJB}_{\mathrm{S}}\right)$

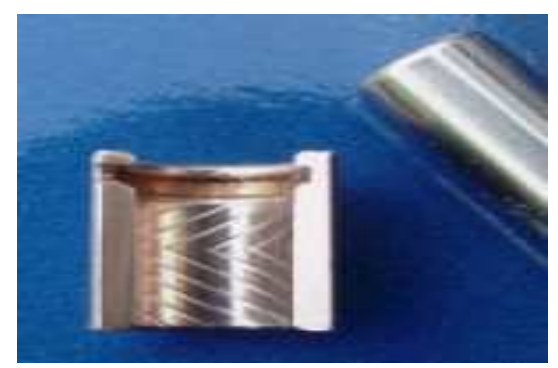

Fig. 2 Fully $\left(\mathrm{HGJB}_{\mathrm{S}}\right)$

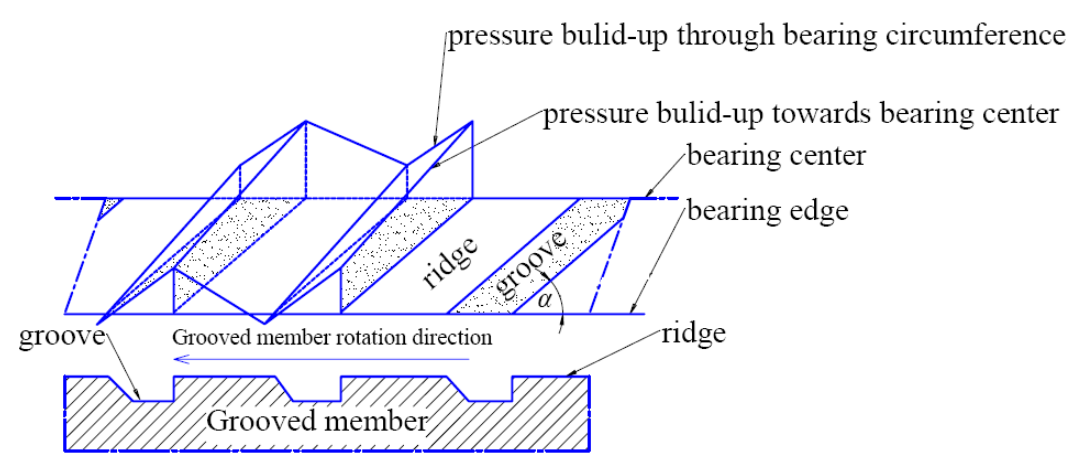

Fig. 3 Approximate pressure build-up above grooved member

Groove profile plays a vital role in controlling the performance characteristics of HGJB $_{\mathrm{S}}$. Recently Gad et al. [1] introduced beveled-step groove profile which increases the amount of oil pumped inward and capable of increasing the pressure recovery at the divergence of the flow over the step and the performance characteristics of the beveled-step completely HGJBs was determined experimentally. But fully grooved bearing designs give maximum high speed stability but at the expense of bearing stiffness [25] and load carrying capacity of the fully HGJBs are small at high eccentricity ratios [19]. 
In the present work, a combination between partially herringbone groove pattern and beveled-step groove profile for the HGJBs were introduced. This combination effectively enhances the bearing load carrying capacity due to higher pressure development in the bearing area, maximizes radial stiffness and maintains the bearing stability. An optimization of the bearing parameters are carried out and the characteristics of oil-lubricated beveled-step partially $\mathrm{HGJB}_{\mathrm{S}}$ are experimentally investigated for the optimized bearing. After optimization a comparison with experimental results for the completely grooved bearing which have the same beveledstep groove profile [1], and rectangular groove profile [24] had been performed.

\section{EXPERIMENTAL WORK}

Experimental testing was carried out on a 20 grooved rotors. The grooves where cut on the rotor surface and have a partially Herringbone pattern and each groove has a beveled-step geometry Fig. 4-a, 4-b. The inscribed grooves were cut on a conventional center lathe as a right and left hand screw using a designed high speed steel (HSS) tool, which has the same beveled-step groove profile Fig.4-c, the bevel angle $(\Theta)$ was checked by a profile projector and held constant for all specimens and was equal to about $30^{\circ}$ and the tool tip width (d) was calculated from the relation:

$$
d=\frac{\beta \pi D}{N_{g}} \sin \alpha-\frac{C(\Gamma-1)}{\tan \Theta}
$$

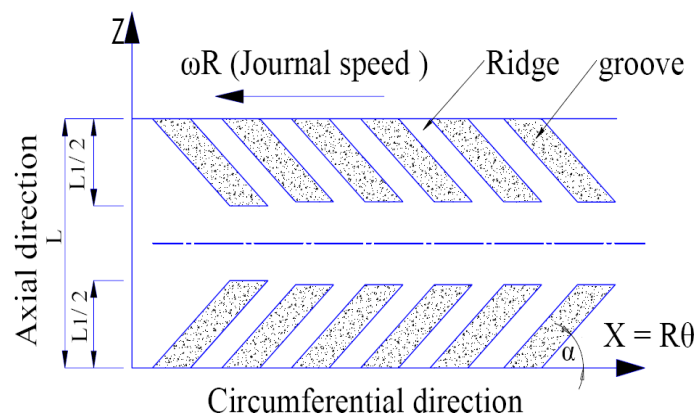

4-a. Partially HGJBs.

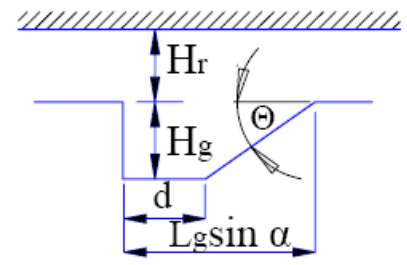

Section X-X
$\beta=\mathrm{Lg} /(\mathrm{Lg}+\mathrm{Lr})$

$\Gamma=\left(\mathrm{Hg}_{\mathrm{g}}+\mathrm{H}_{\mathrm{r}}\right) / \mathrm{Hr}$

$\lambda=\mathrm{L} 1 / \mathrm{L}$

$\Theta=30^{\circ}$

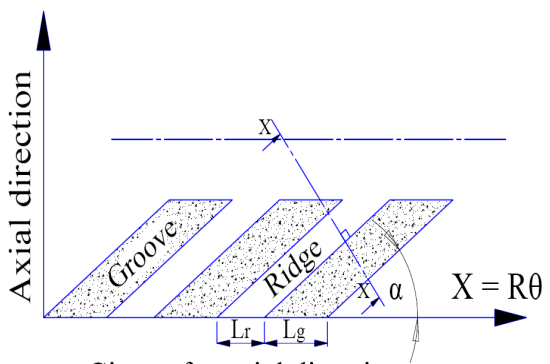

Circumferential direction

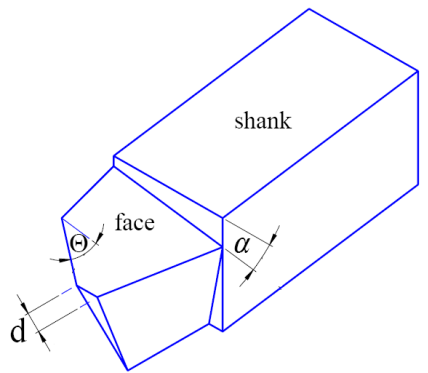

4-b. beveled-step groove profile 4-c. high speed steel cutting tool

Fig.4 Geometry of groove profile and cutting tool 
The manufactured specimens have a combination between groove width ratios $(\beta)$, groove depth ratios $(\Gamma)$ and groove angles $(\alpha)$. Table 1 shows the specimen's specifications. An optimization for these parameters was done for obtaining the best stability characteristics.

Table 1. Specimens' specification

\begin{tabular}{|c|c|c|}
\hline groove width ratio $(\beta)$ & groove depth ratio $(\Gamma)$ & $\begin{array}{c}\text { groove angle }(\alpha) \\
\text { degree }\end{array}$ \\
\hline 0.45 & 2.2 & $24.42^{\circ}, 26.78^{\circ}, 29.05^{\circ}, 31.2^{\circ}$ \\
\hline 0.50 & 2.2 & $24.42^{\circ}, 26.78^{\circ}, 29.05^{\circ}, 31.2^{\circ}$ \\
\hline 0.55 & 2.2 & $24.42^{\circ}, 26.78^{\circ}, 29.05^{\circ}, 31.2^{\circ}$ \\
\hline 0.6 & 2.2 & $24.42^{\circ}, 26.78^{\circ}, 29.05^{\circ}, 31.2^{\circ}$ \\
\hline 0.55 & $1.62,2.0,2.2,2.5$ & $26.78^{\circ}$ \\
\hline
\end{tabular}

A hydrodynamic lubrication unit [26] consisting of a rigid tubular steel frame is used. The unit is equipped with a pneumatically operated pressurized oil supply, D.C solid state, and variable speed control unit. Schematic representation of the used experimental apparatus is shown in fig 5.

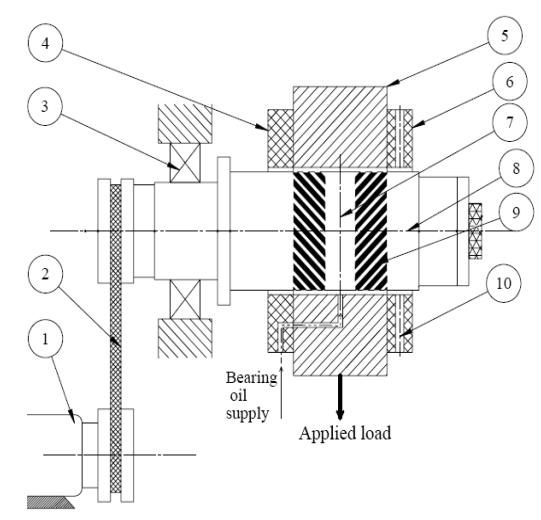

1-D.C drive motor

2-Belt drive

3-Ball bearing

4-Rear drain ring

5-Bearing housing

6-Front drain ring

7-Herringbone center

8-Journal

9-Partially herringbone grooves

10-Air nozzle

Pressure profiles around the grooved bearing were estimated using pressure distribution apparatus Fig. 6, which consist of a bearing housing with 12 circumferentially, distributed drilled and lapped axial passages with step angle of 20 degrees between for measuring of oil pressure over the grooved bearing surface .Each axial passage has five pressure taps distributed in the axial direction. For ease of manufacture the bearing housing is made in two halves. The pressure measurements is made using a pressure probe consisting of a bourdon tube gauge mounted in accurately lapped spool which is used to traverse the drilling in the bearing block. Five markings on the spool shown the position when the probe is correctly aligned with the pressure taps in the axial direction, thus the pressure was measured on 60 points over the bearing circumference. Because the bearing housing was manufactured as two halves it was difficult to measure the pressure near the interface between the two halves. As a result of such consideration the pressure at the not drilled holes $(7,8,9,16,17$ and18) was obtaining by linear interpolation between the measured values. The bearing is 
supplied by oil of pressure from 0.5 to 1.2 bars according to the loading conditions. After oil is flowing through the bearing the dead weight is applied to the mass hanger and the rotational speed is increased gradually to avoid oil film rupture. By using the provided contact meter a contact between the bearing and journal checked to insure that there is no surface contact so a stable hydrodynamic film is formed and the apparatus ready for pressure measurements. Thermometer was used to measure the oil outlet temperature at the start and end of experiments and the average temperature was determined in order to determine the average oil viscosity during the experiments.

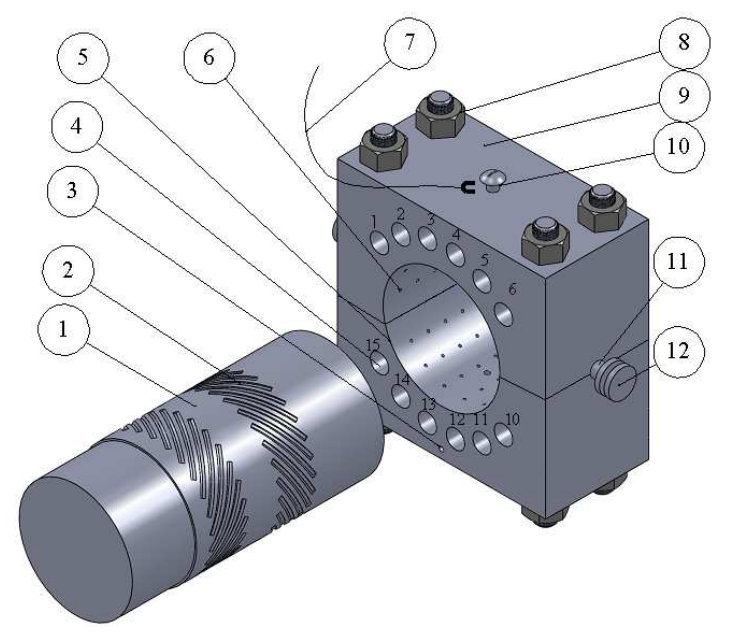

1- Partially herringbone Grooved

1. journal.

2- Partially beveled-step grooves.

3- Oil inlet hole.

4- Axial passages for Pressure

2. measurement.

5- Bearing housing (bottom half).

6- Oil tap.

7- Contact meter lead.

8- Clamping stud.

9- Bearing housing (upper half).

10- Contact meter set screw.

11- Mass hanger location.

12- Bearing latch location.

Fig. 6 Pressure distribution apparatus

Eccentricity in $\mathrm{X}, \mathrm{Y}$ directions and attitude angle were measured using the apparatus shown in Fig.7.The bearing bush is fitted in the inner diameter of bottom and upper halves no. 2, 3 of bearing housing. The hydrostatic pad is fitted to the outer diameter of the upper housing half no. 3. The apparatus consists of a pair of calibrated orthogonally air nozzles schematically shown in Fig. 8 were located in the same radial plane and outboard of the bearing. These air nozzles provided a non contacting method of detecting radial displacements of the bearing. The nozzles were provided with two pressure gauges with air regulating valves and micrometer calibration fixture. The variation of the gap size between the rotating journal and the nozzles causes a corresponding variation of nozzle pressure, then the gap size in $\mathrm{X}$ and $\mathrm{Y}$ directions can be determined, so the bearing center can be known and attitude angle and eccentricity in $\mathrm{X}$ and $\mathrm{Y}$ directions can be determined.

Friction torque which is produced by frictional forces and opposes rotational motion has an important influence on the power required in a bearing drive system. Friction torque is measured using the friction torque apparatus, Fig. 7 in conjunction with a torque transducer. The torque transducer is positioned in the unit frame and the torque wire is positioned horizontally over the torque pin no. 7 , thus any displacement of the bearing, caused by friction torque can be directly measured.

A calibration process for all used instruments (tachometer, torque meter, contact meter, pressure gauges, and air nozzles) were carried out and the oil viscosity at various temperatures was checked using Redwood 1 viscometer. 


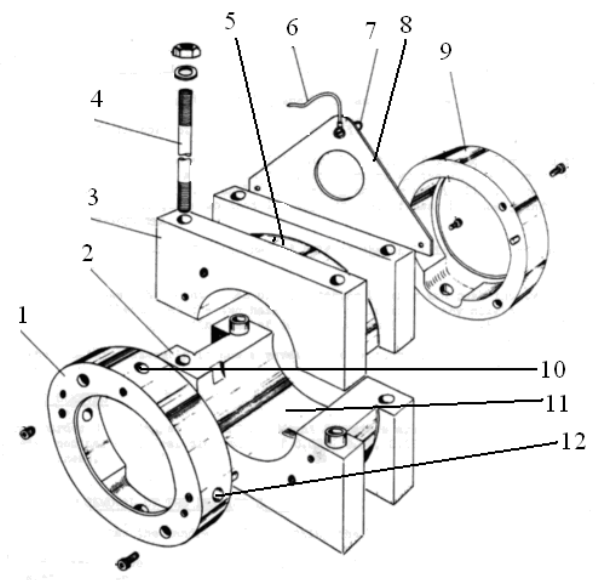

1-Front drain ring

2-Bearing housing (bottom half)

3-Bearing housing (upper half)

4-Clamping stud

5-Hydrostatic pad location

6-Contact meter lead

7-Torque pin

8-Torque plate

9-Rear drain ring

10- Y nozzle location

12- X nozzle location

Fig. 7 Friction torque, contact and attitude measuring apparatus

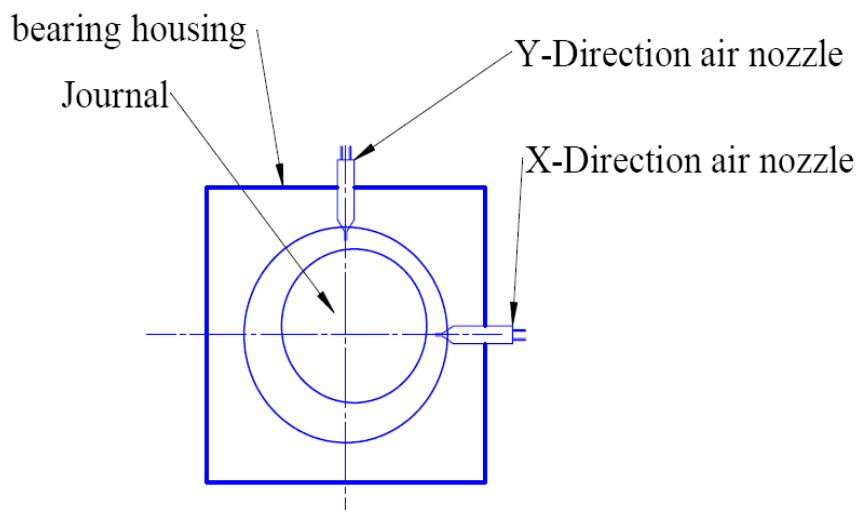

Fig.8 X-Y directions air nozzles.

\section{RESULTS AND DISCUSSION}

Experiments were carried out to the study the effect of varying the groove parameters $(\alpha, \beta, \Gamma)$ on the performance of partially beveled-step HGJBS .Table 2 shows the geometrical and operating conditions of partially HGJBs which were used in experiments to optimize the groove angle $(\alpha)$ and groove width ratio $(\beta)$ that give maximum radial force and maximum radial stiffness. Through these experiments the groove depth ratio $(\Gamma)$ and groove length ratio $(\lambda)$ was held approximately constant and equal 2.2 and 0.67 respectively. The number of grooves $\left(\mathrm{N}_{\mathrm{g}}\right)$ where cut on the journal circumference are 25 groove therefore the narrow groove theory (NGT) can be applied according to Chow and Vohr[5].

Bearing load capacity, stiffness, radial and tangential forces are directly related to the pressure distribution, once the pressure distribution is obtained, the characteristic parameters of the bearings can be derived. The dimensionless pressure over the bearing surface was measured and equal to:

$$
\bar{P}=\frac{P}{\mu \omega}\left(\frac{C}{R}\right)^{2}
$$


Table 2.Geometrical and operating conditions of partially beveled-step $\mathrm{HGJB}_{S}$

\begin{tabular}{|l|l|}
\hline Grooved rotated member & Journal \\
Numbers of grooves, Ng & 25 groove \\
Journal diameter, D & $50.47 \mathrm{~mm}$ \\
Bearing length , L & $44.5 \mathrm{~mm}$ \\
Nominal clearance, C & $0.075 \mathrm{~mm}$ \\
Groove width ratio, $\beta$ & $0.45,0.50,0.55,0.60$ \\
Groove angle, $\alpha$ & $24.42^{\circ}, 26.78^{\circ}, 29.05^{\circ}, 31.2^{\circ}$ \\
Rotational speed , $\omega$ & $1000 \mathrm{rpm}$ \\
Applied load & $200 \mathrm{~N}$ \\
Oil viscosity, $\mu$ & $0.02 \mathrm{pa} . \mathrm{s}$ \\
Ambient pressure pa & $1.0 \mathrm{bar}(1.013 \times 105 \mathrm{~N} / \mathrm{m} 2)$ \\
\hline
\end{tabular}

Figure 9 shows the dimensionless pressure profile around the bearing circumference at the axis of bearing symmetry and close to the bearing edge .The pressure was measured for different groove angles and groove width ratios.

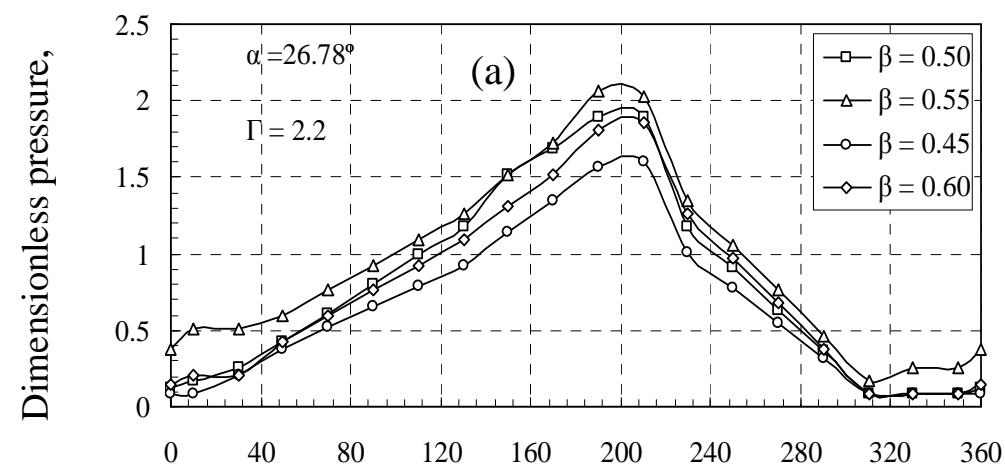

(a) Angle ( $\Phi)$ circumferential direction

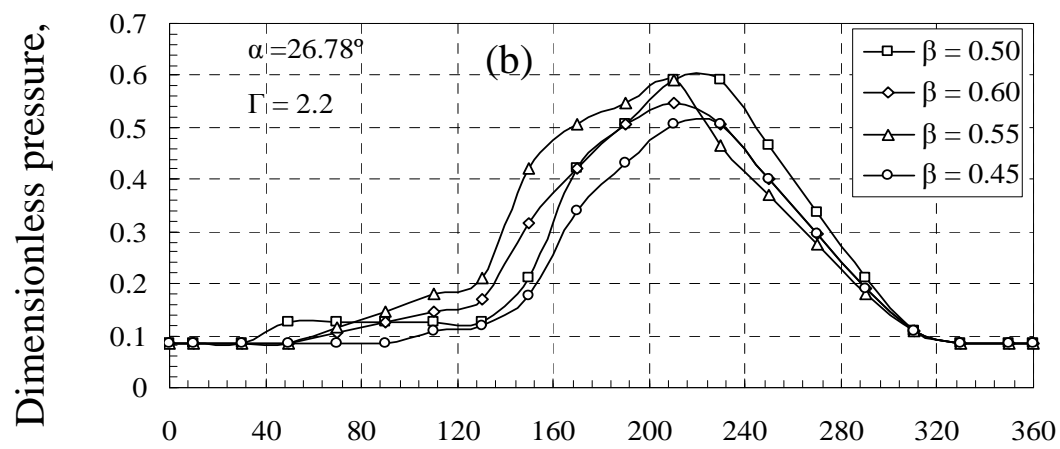

(b) Angle ( $\Phi)$ circumferential direction

Fig. 9. Dimensionless pressure distributions. (a) At the axis of bearing symmetry. (b) Close to the bearing edge. 
From Fig. 9, it's clear that in addition to high pressure values in convergent region a positive pressure appears at the divergent region. This positive pressure diminishes in the case of plain journal bearing, [19].This result also agrees with the foregoing literature result in [1,11 and19]. The appearance of this high pressure in the convergent region and the positive pressure in divergent region is a result of pressure build up due to beveled-step grooves pumping effect which reducing the side leakage as well as increasing the stability of the bearing system.

Figure 10 shows the variation of dimensionless pressure through the bearing axial direction at the angle $(\Phi)$ of $200^{\circ}$ which measured from negative $\mathrm{Y}$ axis and in the direction of journal rotation at various groove width ratios. It can be seen from this figure that there is large pumping action in axial directions too.

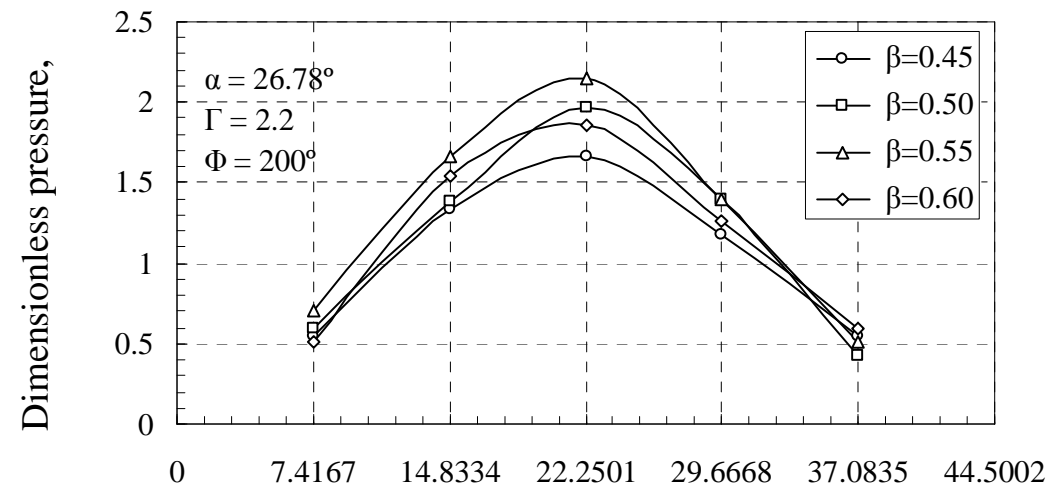

Axial distance from bearing edge, $\mathrm{mm}$

Fig. 10 Variation of dimensionless pressure through the axial direction at the angle $(\Phi)$ of $200^{\circ}$, groove angle $(\alpha)=26.78^{\circ}$.

The angle measured between the applied load line and the line of centers is known as attitude angle, the large attitude angles are indicative of large tangential destabilizing stiffness in the bearing. Fig. 11 shows the variation of bearing attitude angle $(\varphi)$ with groove angle $(\alpha)$ at various groove depth ratios. The figure shows that the attitude angle reaches its lower values for groove width ratios of 0.55 and 0.50 at groove angle of $26.78^{\circ}$, and groove angle of $29.05^{\circ}$ for groove width ratios of 0.60 and 0.45 . The low value of attitude angles for $\beta=0.55$ and $\alpha=26.78^{\circ}$ is due to minimum tangential force at this parameters.

Through this research a dimensionless radial stiffness $\bar{F}_{R}$ which introduced by [24] and used by [1] has been also used to optimize the groove parameters that gives maximum load carrying capacity, maximum radial force and radial stiffness. The dimensionless radial stiffness is calculated as:-

$$
\bar{F}_{R}=\frac{2 \pi \bar{W} \cos \varphi}{\varepsilon}
$$

Where $\bar{W}$ is dimensionless load carrying capacity and expressed as:

$$
\bar{W}=\frac{W}{\mu \omega L D}\left(\frac{C}{R}\right)^{2}
$$




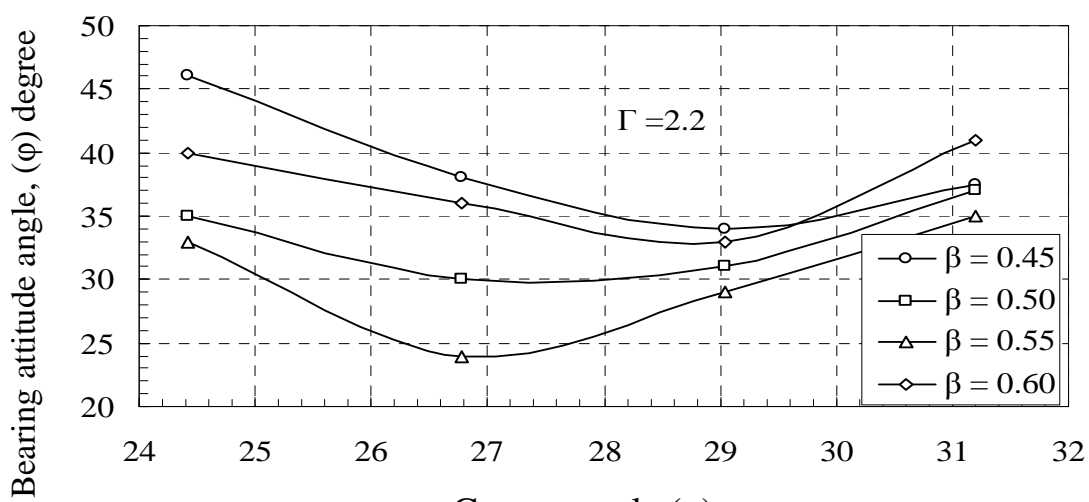

Groove angle $(\alpha)$

Fig.11 Variation of bearing attitude angle $(\varphi)$ with groove angle $(\alpha)$ at various groove depth ratios and $\Gamma=2.2$.

Figure 12 shows the variation of radial stiffness $\bar{F}_{R}$ with groove angle at various groove width ratios. It is shown from the figure that the radial stiffness reaches its maximum value for all groove width ratios at groove angle of $\alpha=26.78^{\circ}$ and $\Gamma=2.2$ .The maximum radial stiffness occurs at groove angle $\alpha=26.78^{\circ}$ and $\beta=0.55$.

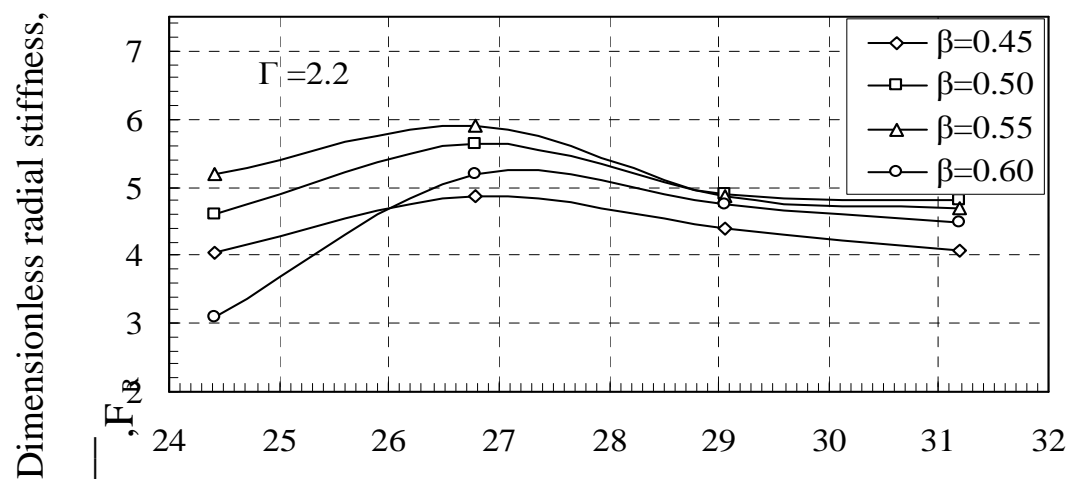

Groove angle $(\alpha)$

Fig. 12 Variation of radial stiffness with groove angle at various groove width ratios and $\Gamma=2.2$.

The influence of load carrying capacity of beveled-step partially $\mathrm{HGJB}_{\mathrm{S}}$ on the groove angle at various groove width ratios and $\Gamma=2.2$ are shown in Fig. 13. The maximum load carrying capacity occurs at groove angle $\alpha=26.78^{\circ}$, groove width ratio $\beta=0.55$ and $\Gamma=2.2$.

From the previous results of radial stiffness and load carrying capacity, it can be concluded that the optimum groove angle and groove width ratio are $26.78^{\circ}$ and 0.55 respectively.

Different groove depths have been investigated. Table 1 shows the tested groove depth ratios and Fig. 14 shows the nondimensional pressure profiles at various groove depth ratios. The pressure increases with the increase of groove depth ratio until 
the maximum pressure at the value of $\Gamma=2.2$.after that the pressure decreased with increasing in groove depth ratio. The optimum value of groove depth ratio for beveledstep partially $\mathrm{HGJB}_{\mathrm{S}}$ is about $\Gamma=2.2$.

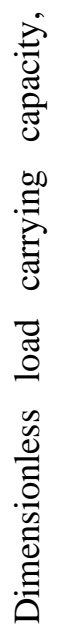

0.9

0.85

0.8

0.75

0.7

0.65

0.6

0.55

0.5

0.45

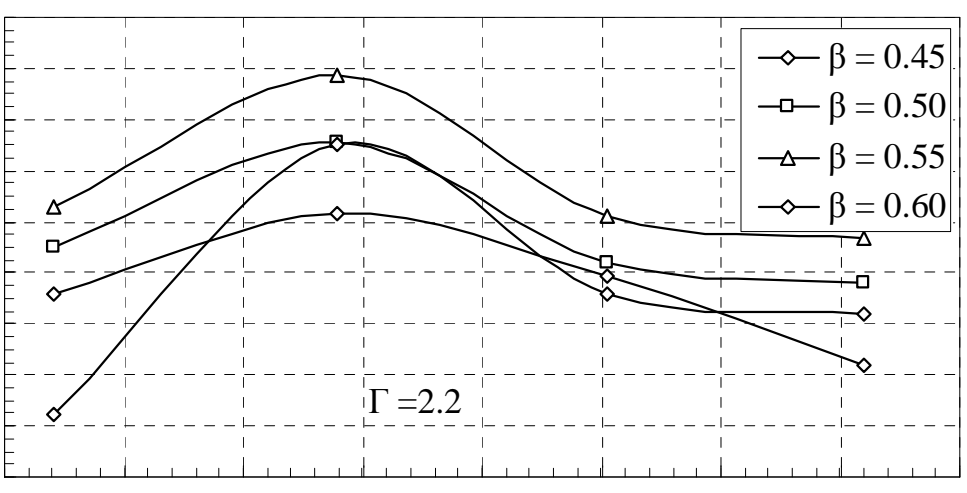

24

25

26

$27 \quad 28$

29
$30 \quad 31$

32

Groove angle $(\alpha)$

Fig.13 Variation of load carrying capacity with groove angle at various groove width ratios and $\Gamma=2.2$

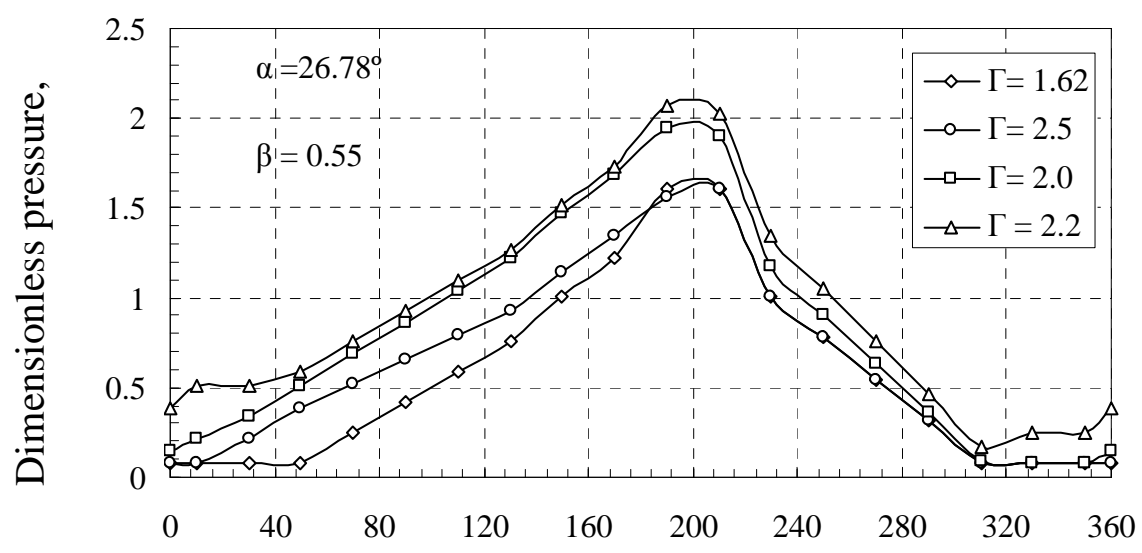

Angle $(\Phi)$ circumferential direction

Fig. 14 Dimensionless pressure distributions at the axis of symmetry around beveledstep partially $\mathrm{HGJB}_{\mathrm{S}}$ for various groove depth ratios at $\alpha=26.78^{\circ}$ and $\beta=0.55$.

\section{COMPARISON BETWEEN BEVELED-STEP PARTIALLY HGJB, BEVELED-STEP COMPLETELY HGJB AND THE COMPLETELY RECTANGULAR HGJB.}

To study the influence of journal groove geometry on the performance of the grooved journal bearing and to check the validity of the obtained experimental results a 
comparison between the introduced partially beveled-step HGJB, experimental results on completely beveled-step HGJB introduced by [1] and theoretical results on completely rectangular HGJB obtained by [24]were carried out. Figures 15, 16, and 17 show the variation of radial stiffness with the groove parameters $\alpha, \beta$ and $\Gamma$. Using the optimal values in each case. From these figures the dimensionless radial force for partially beveled-step HGJB has higher value than completely beveled-step HGJB and completely rectangular HGJB.The maximum value of dimensionless radial stiffness in case of partially beveled-step HGJBs is about $23 \%$ greater than completely beveledstep HGJBs. This increase is due to increase in the resultant pressure at the convergent and divergent regions. From Fig 15, the optimum values for Groove angle that gives maximum radial stiffness are $26.78^{\circ}, 29.05^{\circ}$ and $32.8^{\circ}$ for partially beveled-step HGJB, completely beveled-step HGJB and completely rectangular HGJB respectively. From Fig.16, the optimum groove width ratio of partially beveled-step HGJB is 0.55 and 0 .50 for both completely beveled-step HGJB and completely rectangular HGJB. Fig. 17 shows the optimum value of groove depth ratio is 2.2 for partially beveled-step HGJB and 2.0, 2.1 for completely beveled-step HGJB and completely rectangular HGJB respectively.

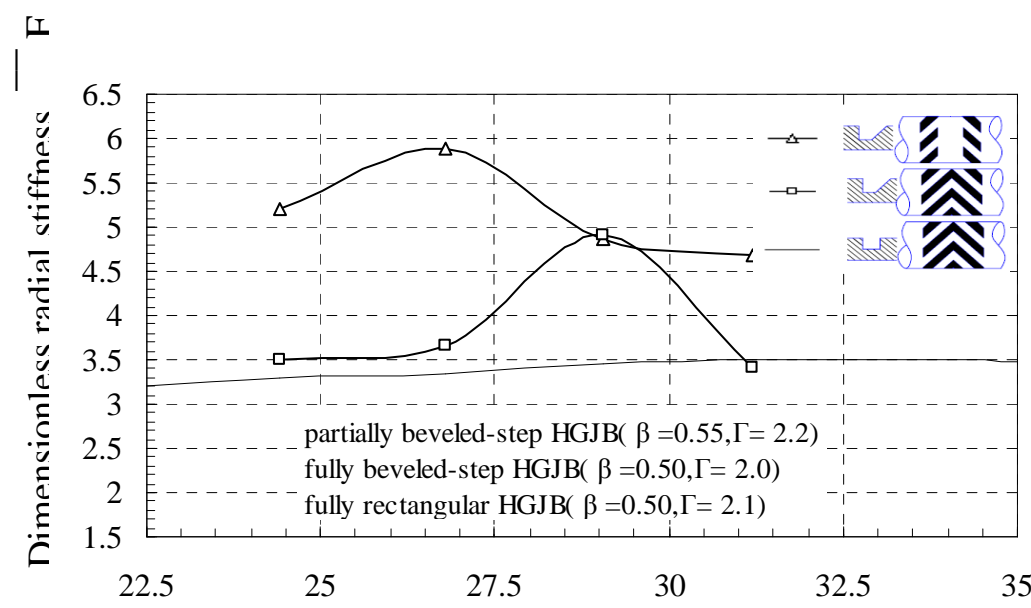

Groove angle $(\alpha)$

Fig. 15 Variation of the dimensionless radial force, $\bar{F}_{R}$ for partially and completely beveled-step HGJB and completely rectangular HGJB with groove angle $(\alpha)$

Figures 18, 19 and 20, show the variation of bearing attitude angle with the groove parameters $\alpha, \beta$ and $\Gamma$. Fig. 18 shows that the attitude angle for partially beveled-step HGJB has lower values until groove angle of $28^{\circ}$. Then the completely beveled-step HGJB have a lower value than both partially beveled-step HGJB and completely rectangular HGJB .A relatively equal attitude angle for both partially and completely beveled-step HGJB at groove angle $\alpha=28^{\circ}$.

In Fig. 19 the completely beveled-step HGJB have minimum attitude angle at groove width ratios 0.45 and 0.50 and equal attitude at 0.55 for both partially and fully beveled-step HGJB. Figure 20, shows that at the attitude angle for partially beveledstep HGJB the attitude angle is less than the attitude for completely beveled-step HGJB 
and completely rectangular HGJB at all values of groove depth ratio. The lower attitude angle is indication for lower tangential force component and this leads to better stability.

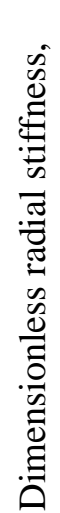

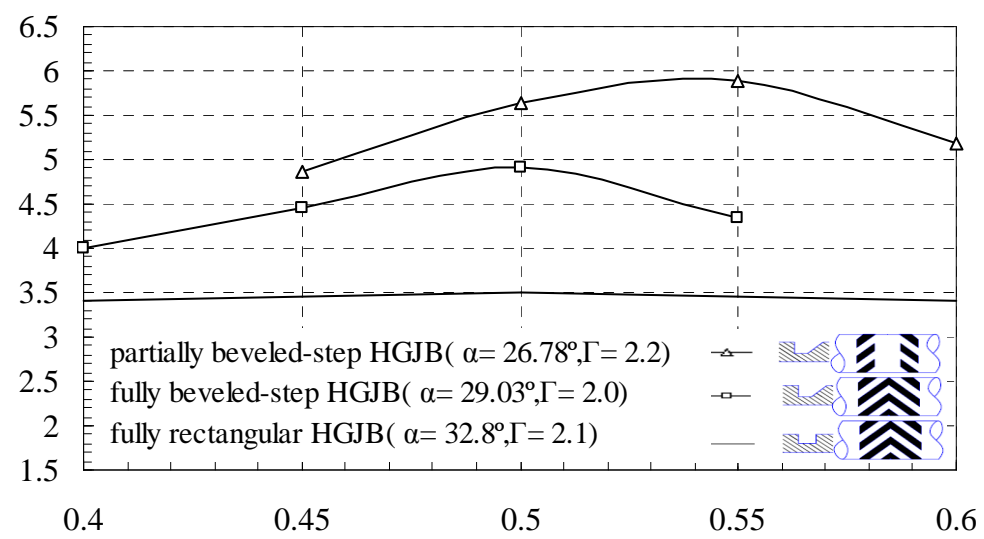

Groove width ratio, $\beta$

Fig. 16 Variation of the dimensionless radial force, $\bar{F}_{R}$ for partially and completely beveled-step HGJB and completely rectangular HGJB with groove width ratio $(\beta)$

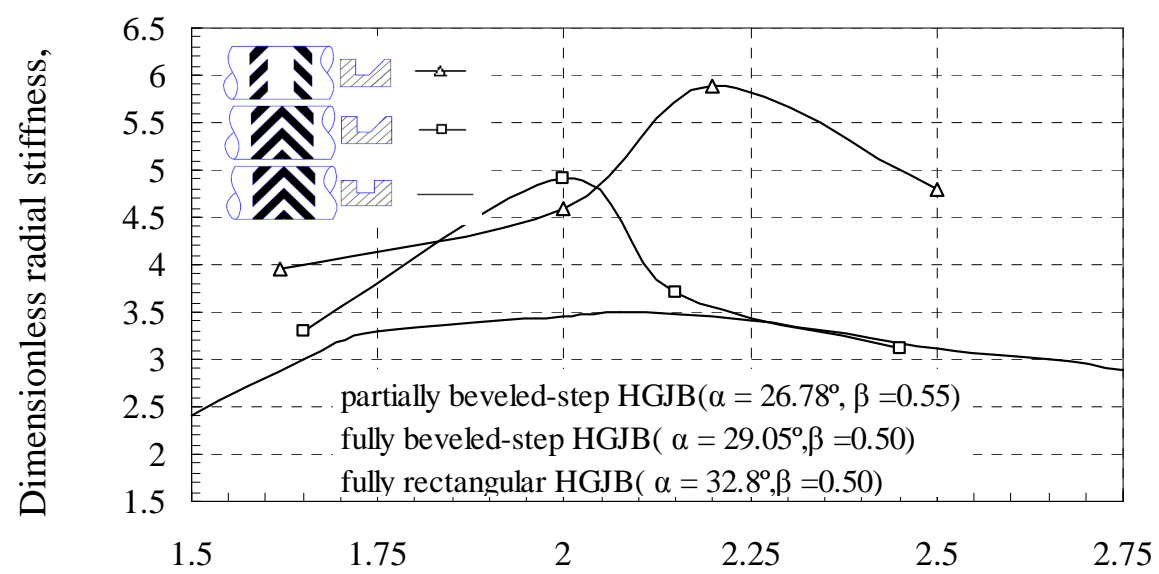

Groove depth ratio, $\Gamma$

Fig. 17 Variation of the Dimensionless radial stiffness, $\bar{F}_{R}$ for partially and completely beveled-step HGJB and completely rectangular HGJB with groove depth $\operatorname{ratio}(\Gamma)$.

Friction torque which is produced by frictional forces and opposes rotational motion has an important influence on the power required in a bearing drive system. In hydrodynamic bearings, friction is a function of lubricant viscosity and shear rate. Friction torque is measured at various rotational speeds and applied loads. 


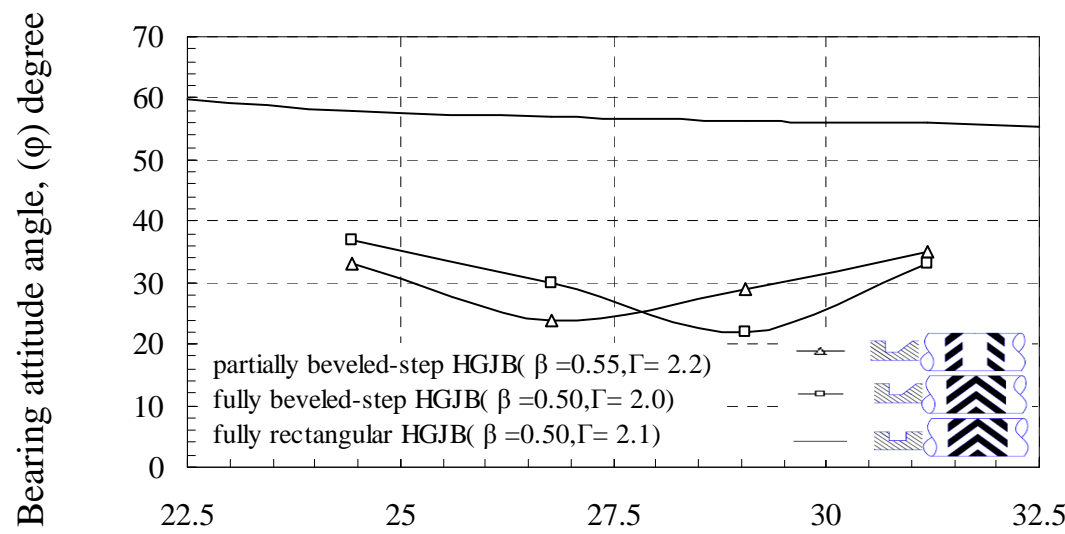

Groove angle $(\alpha)$

Fig.18 Variation of the bearing attitude angle $(\varphi)$ for partially and completely beveledstep HGJB and completely rectangular HGJB with groove angle $(\alpha)$.

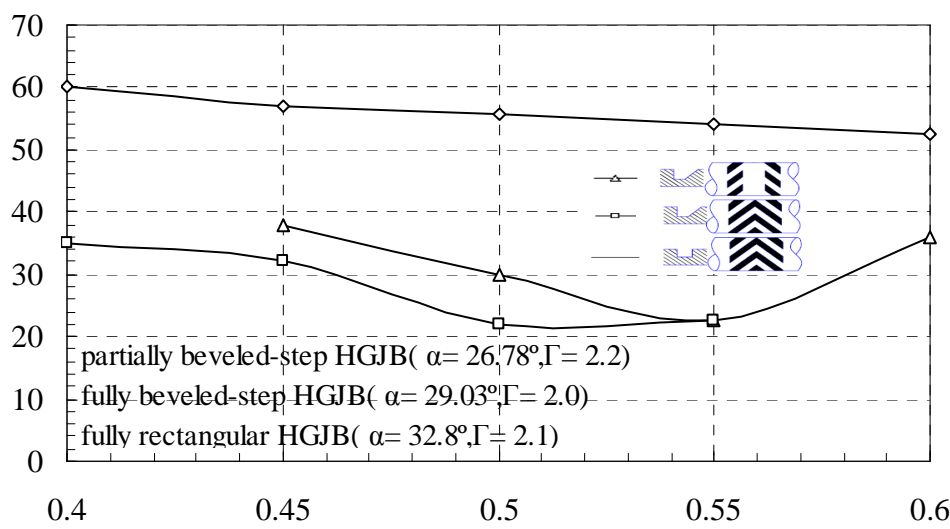

Groove width ratio, $\beta$

Fig.19 Variation of the bearing attitude angle $(\varphi)$ for partially and completely beveledstep HGJB and completely rectangular HGJB with groove width ratio $(\beta)$

Figure 21 shows that the dimensionless friction torque for beveled-step partially HGJB is smaller than of beveled-step fully HGJB until eccentricity ratio of 0.43 , after this ratio the friction torque for partially beveled-step HGJB increased but with small amount than fully beveled-step HGJB. This may be attributed due to decreasing in oil film thickness at high eccentricity ratio. Dimensionless friction torque is expressed as:

$$
\bar{T}_{r}=T_{r}\left(\frac{C}{\mu \omega R^{4}}\right)
$$




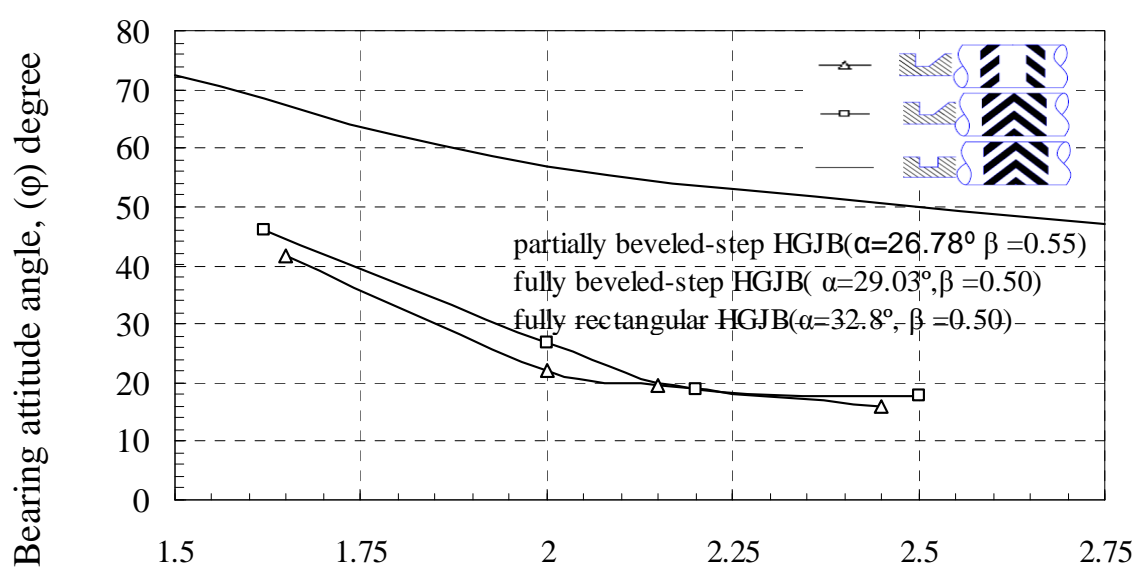

Groove depth ratio, $\Gamma$

Fig. 20 Variation of the bearing attitude angle $(\varphi)$ for partially and completely beveledstep HGJB and completely rectangular HGJB with groove depth ratio, $\Gamma$

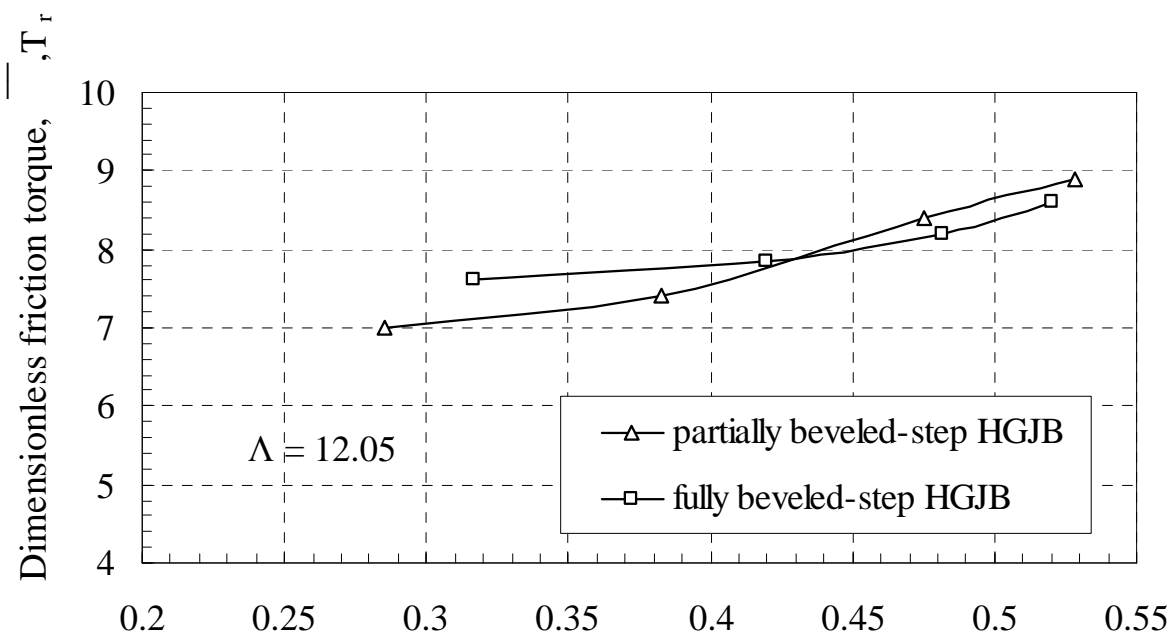

Eccentricity ratio $(\varepsilon)$

Fig.21 Variation of the bearing dimensionless friction torque for partially and completely beveled-step HGJB with eccentricity ratio $(\varepsilon)$.

\section{CONCLUSIONS}

An experimental investigation of the performance characteristics of partially beveledstep HGJB was carried out. The main conclusions conducted from the experimental results as follows:

1- There is a positive pressure that appears at the divergence region between journal and bearing in addition to high pressure values in convergent region.

2- The optimized values of partially beveled-step (HGJBs) parameters were found to be $\left(\alpha=26.78^{\circ}, \beta=0.55, \Gamma=2.2\right)$

3- Partially beveled-step (HGJBs) have large pumping action in both circumferential and axial directions. 
4- Dimensionless radial stiffness in case of partially beveled-step HGJBs is about $23 \%$ greater than completely beveled-step HGJBs

5- Partially beveled-step (HGJBs) have attitude angle in the range of fully beveledstep (HGJBs) and lower than fully rectangular (HGJBs) at the optimized values for groove parameters.

6- Radial force and carrying capacity of grooved bearing can be improved by partialgrooving, provided with beveled-step groove profile.

7- At high speed and small eccentricity ratios (near concentric position) partially beveled-step (HGJBs) have low friction torque.

\section{REFERENCES}

[1] Gad, A. M., Nemat-Alla, M., Khalil, A. A., and Nasr, A. "On the Optimum Groove Geometry for Herringbone Grooved Journal Bearings," ASME J. Tribol., 128 , pp. 585-593,(2006).

[2] S. B, Malanoski, "Experiments on an Ultra-Stable Gas Journal Bearing," Journal of Lubrication Technology, vol. 89, no. 4 October, pp. 433-438, (1967).

[3] Hirs, G.G. "The load capacity and stability characteristics of hydrodynamic grooved journal bearings", ASLE Transactions, Vol. 8, pp. 296-305, (1965).

[4] E. A. Muijderman"Analysis and design of spiral-groove bearings," Journal of lubrication technology, pp.291 -306, (1967).

[5] Chow, C. Y., and Vohr, J. H. "Helical-Grooved Journal Bearing Operated in Turbulent Regime," ASME J. Lubr. Technol., 92, pp. 346-358, (1970).

[6] Bernard J. Hamrock and David P. Fleming . "Optimization of self-acting herringbone journal bearings for maximum radial load capacity "NASA TN D6351, (1971)

[7] Bootsma, J. "The gas liquid interface and the load capacity of helical grooved journal bearings," ASME J. Lubr. Technol., 92, pp.94-100, (1973).

[8] Kawabata, N., Ozawa, Y., Kamaya, s., and Miyake, Y. "Static Characteristics of the Regular and Reversible Rotation Type Herringbone Grooved Journal Bearing", ASME Journal of tribology : Vol. 111, pp. 484-490, (1989).

[9] S. Yoshimoto, Y. Ito., and A. Takahashi "Pumping Characteristics of a Herringbone-Grooved Journal Bearing Functioning as a Viscous Vacuum Pump", ASME Journal of Tribology: Vol. 122, pp. 131-136, (2000).

[10] Kang, K., Rhim, Y., and Sung, K., "A Study of the Oil-Lubricated HerringboneGrooved Journal Bearing-Part 1: Numerical Analysis," ASME J. Tribol., 118, pp. 906-911,( 1996).

[11]Bonneau, D., and Absi, J., "Analysis of Aerodynamic Journal Bearings with Small Number of Herringbone Grooves by Finite Element Method," ASME J. Tribol., 116, pp. 698-704, (1994).

[12] Kinouchi, K., Tanaka, K., Yoshimura, S., andYagawa, G., "Finite Element Analysis of Gas-Lubricated Grooved Journal Bearing (Analysis Method)," JSME, 39, pp.123-129, (1996).

[13]Zirkelback, N., and San Andres, L., "Finite Element Analysis of Herringbone Groove Journal Bearings: A Parametric Study,” ASME J. Tribol.,120, pp. 234240, (1998). 
[14]Faria,M.T.C., "Some Performance Characteristics Of High Speed Gas Lubricated Herringbone Groove Journal Bearings," JSME, 44, pp.775 779,(2001).

[15]Jang, G. H., and Yoon, J. W., "Nonlinear Dynamic Analysis of a Hydrodynamic Journal Bearing Considering the Effect of a Rotating or Stationary Herringbone Groove," ASME J. Tribol., 124, pp. 297-304,(2002).

[16]Jang, G. H., and Yoon, J. W., "Stability Analysis of a Hydrodynamic Journal Bearing With Rotating Herringbone Grooves," ASME J. Tribol., 124, pp. 291300,( 2003).

[17]Jang, G. H., Lee ,S. H.,and Kim, H. W., "Finite Element Analysis of the Coupled Journal and Thrust Bearing in a Computer Hard Disk Drive ," ASME J. Tribol., 128, pp.335-340,( 2006).

[18]Kobayashi,T., "Numerical Analysis of Herringbone-Grooved Gas-Lubricated Journal bearings Using a Multigrid Technique," ASME J. Tribol., 121, pp.148156,( 1999).

[19]T.S. Lee, Y.G. Liu and S.H. Winoto , "Analysis of liquid-lubricated herringbone grooved journal bearings," International Journal of Numerical Methods for Heat \& Fluid Flow,Vol. 14 No. 3,pp. 341-365, ( 2004)

[20]Hirayama ,T., Sakurai ,T.,and Yabe , H., "A Theoretical Analysis Considering Cavitation Occurrence in Oil-Lubricated Spiral-Grooved Journal Bearings With Experimental Verification ," ASME J. Tribol., 126, pp.490-498,(2004).

[21] Cheng-Chi Wang., "Theoretical and nonlinear behavior analysis of a flexible rotor supported by a relative short herringbone-grooved gas journal-bearing system," Physica D 237 ,2282-2295, (2008).

[22] Bootsma,J., and Tielemanas ,L.P.M., "Condition Of Leakage-Free Operation Of Herringbone Grooved Journal Bearing," ASME J. Lubr. Technol., pp.215-223, (1979).

[23] Burton,R.A., "An Experimental Study Of Turbulent Flow In a Spiral-Groove Configuration ,’ ASME J. Lubr. Technol., pp.443-449, (1968).

[24] Vohr, J. H. and C. Y. Chow, 1965, "Characteristics of Herringbone-Grooved GasLubricated Journal Bearings," ASME Journal of Basic Engineering, Vol. 87, pp. 568-578.

[25]P. Stanev, F. Wardle and J. Corbett, Grooved hybrid air bearings, http://www.loadpoint.co.uk/site2/grooved.pdf (accessed on 6th January 2008).

[26] Cussons Technology Ltd,102 Great Clowes Street, Manchester M7 1RH, England "Instruction Manual for Hydrodynamic lubrication unit P5013" . 


\section{خواص كرسى محور يعمل بالزيت بة مجارى على شكل جزء من هيكل الرنجة.}

تم اجراء فحص معملى لاداء كرسى محور يعمل بالزيت بـة مجارى على هيئة جزء من هيكل الرنجة

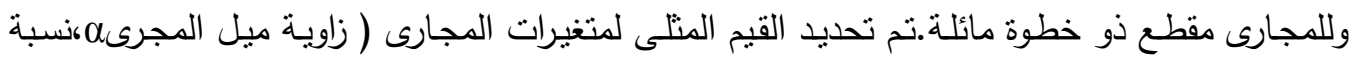

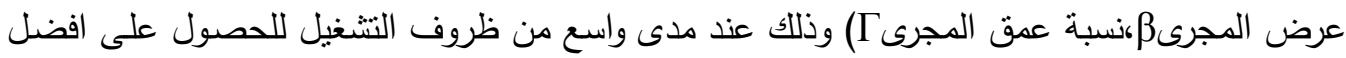

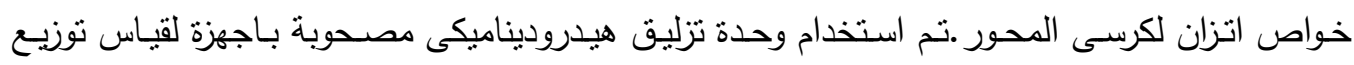

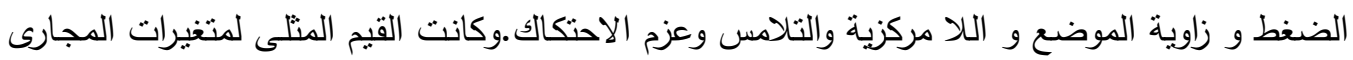

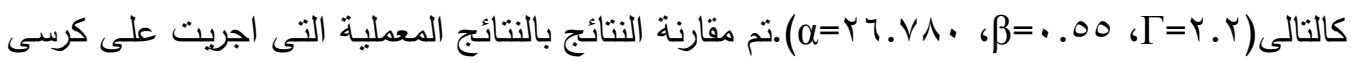

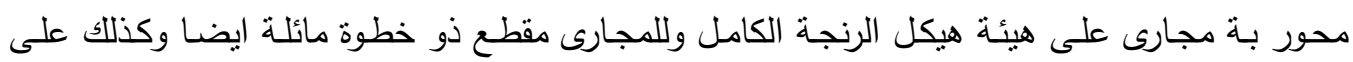

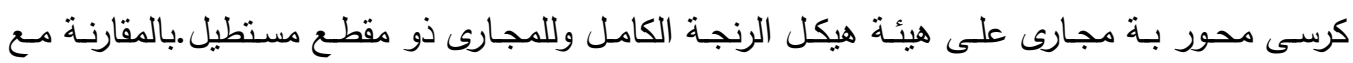
الاعمال السابقة وجد ان الثكل المقدم فى هذا البحث اظهر قيم كبيرة لكل من الجسائة النصف قطرية وسعة التحميل وقيم صغيرة لعزم الاحتكاك وكذلك خواص اتزان افضل. 

Journal of Engineering Sciences, Assiut University, Vol. 37, No. 4, pp. 925-942, July 2009.

\section{NOMENCLATURES}

C Radial clearance at concentric position, $m$

D Journal diameter, $m$

d Tool tip width, $m$

e Journal eccentricity

$\overline{\mathrm{F}}_{\mathrm{R}} \quad$ Dimensionless radial stiffness

$\mathrm{Hg} \quad$ Groove depth, $\mathrm{m}$

$\mathrm{Hr} \quad$ Oil film thickness in ridge region, $\mathrm{m}$

L Bearing length, $m$

Lg Groove length in the circumferential direction, $m$

Lr Ridge length in the circumferential direction, $m$

$\mathrm{Ng} \quad$ Number of grooves

$\mathrm{P} \quad$ Hydrodynamic oil film pressure, $\mathrm{N} / \mathrm{m}^{2}$

$\overline{\mathrm{P}} \quad$ Dimensionless pressure

$\mathrm{Pa}$ Ambient pressure, $\mathrm{Pa}=1.0$ bar

$\mathrm{R}$ Journal radius, $\mathrm{m}$

$\mathrm{T}_{\mathrm{r}} \quad$ Bearing friction torque, $\mathrm{N} \mathrm{m}$

$\overline{\mathrm{T}}_{\mathrm{r}} \quad$ Dimensionless friction torque

W Load carrying capacity, $\mathrm{N}$

$\bar{W} \quad$ Dimensionless load carrying capacity

$\mathrm{X}, \mathrm{Y}, \mathrm{Z}$ Coordinate system fixed to the bearing 